Check for updates

Cite this: J. Mater. Chem. A, 2017, 5 , 10909

Received 6th April 2017

Accepted 9th May 2017

DOI: $10.1039 / \mathrm{cta02983g}$

rsc.li/materials-a

\section{Self-regulating reversible photocatalytic-driven chromism of a cavity enhanced optical field $\mathrm{TiO}_{2} / \mathrm{CuO}$ nanocomposite $\uparrow$}

\author{
Minmin Gao, id $\ddagger^{\mathrm{a}}$ Serene Wen Ling $\mathrm{Ng}, \ddagger^{\mathrm{ab}}$ Lianwei Chen, ${ }^{\mathrm{a}}$ Minghui Hong ${ }^{\text {ab }}$ \\ and Ghim Wei Ho iD *ab
}

Over the years, the exploration of inorganic chromogenic materials commonly interfaced with expensive noble metals has been limited, while the study of organic photochromic materials has proliferated. The key challenge lies in the optimization of inorganic materials' constituents and structural design to achieve enhanced light-matter interaction chromism with performance commensurate with that of their organic counterparts. Here, we demonstrate a tailored inorganic transition metal cavity that boosts optically controlled reversible and repeatable chromism driven by a photocatalytic reaction. The solution-processable $\mathrm{TiO}_{2} / \mathrm{CuO}$ nanocomposite is endowed with a mesoporous cavity that is highly adept at performing self-regulating reversible photochromism under solar irradiation. The improved photoreactive chromism stems from the tailored critical structural parameters of the highly accessible mesoporous shell, reduced charge carrier diffusion length thin shell, and cavity enhanced optical field for photon-matter interactions. Consequently, the nanocomposite exhibits dual-functional photoregulated effects, i.e. photochromism mediated light transmittance modulation and rewritable printing/patterning. The nanocomposite offers high sensitivity, resulting in a short response time due to the efficient charge transfer, and such chromism effects are stable in the ambient environment. Furthermore, controlled switching of the chromism effects may be obtained simply by low-temperature heating. The concerted combination of inexpensive materials/production, low toxicity and a highly transparent noble metal-free inorganic nanocomposite renders chromogenic properties that will trigger a renewed interest in smart light-stimulus integrated technology.

\section{Introduction}

Materials that self-regulate their color in response to electromagnetic radiation stimuli are important in emerging smart dynamic technologies. The sensitivity of the materials to light radiation makes them useful for a wide variety of applications, i.e. photolithography, self-developing photography, dosimetry and camouflage, etc. ${ }^{1-3}$ Materials with good photochromic reversibility have potential applications in reusable optical memories, information storage media, data displays, sensors and smart windows. ${ }^{1-4}$ Thus far, most photochromic materials are organic-based and are well known to undergo reversible

\footnotetext{
${ }^{a}$ Department of Electrical and Computer Engineering, National University of Singapore, Singapore 117576, Singapore.E-mail: elehgw@nus.edu.sg

${ }^{b}$ Engineering Science Programme, National University of Singapore, 4 Engineering Drive 3, 117576, Singapore

$\dagger$ Electronic supplementary information (ESI) available: Experimental and computational details, SEM and TEM images, XRD spectra, hydrogen production rate, nitrogen adsorption-desorption isotherm and the pore size distribution curves, calculation of optical properties, digital photos and UV-vis measurements of photochromic patterning. See DOI: 10.1039/c7ta02983g

\$ These authors contributed equally to the paper.
}

colour switching based on photochemical and/or thermal conversion. ${ }^{5}$ The significant colour change under stimuli makes them promising materials for rewritable imaging/printing/ display media. This provides a vital solution for reducing the usage of traditional paper for temporary information storage/ display, thus helping to minimise wastage of both paper and ink, as well as the associated environmental issues. ${ }^{6,7}$ However, there has not been a substantial amount of research done on photochromic materials in this area. ${ }^{7,8}$ This is mainly due to a few limitations, i.e. generally slower colour change in solid media than in solution form due to the restricted molecular mobility; ${ }^{9}$ progressive degradation with prolonged exposure to light, which limits its rewritability and outdoor applications; ${ }^{\mathbf{8 , 1 0}}$ and short colour retention from a few minutes to several hours under ambient conditions due to visible-light stimulated decolourization processes. ${ }^{\mathbf{1 1 - 1 3}}$ Moreover, the toxicity of organic dyes may give rise to potential safety and environmental issues. ${ }^{6,10}$

On the other hand, the exploration of inorganic materials' photochromism has been limited, though these materials are known to possess apparent advantages, such as superior thermal stability, strength and chemical resistance, over their 
organic counterparts. ${ }^{3}$ The challenge lies in the optimization of inorganic composite materials for light manipulation and efficient charge interactions at the molecular level. ${ }^{3}$ Among the inorganic materials, $\mathrm{TiO}_{2}$-based photochromogenic materials are widely interfaced with a noble metal, ${ }^{\mathbf{1 4}}$ predominantly a $\mathrm{Ag}$ compound, to capture the photoexcited electrons from $\mathrm{TiO}_{2}$ and reduce silver ion to the metallic state based on a photocatalytic reduction reaction. ${ }^{15-22}$ The heterogeneous $\mathrm{TiO}_{2}$-metal is widely pursued in photocatalytic reactions to counteract the inherent shortcomings of rapid charge recombination in $\mathrm{TiO}_{2} \cdot{ }^{23-25}$ Thus, the tuning of photochromic properties to achieve desirable performance in a rewritable imaging/printing medium can be done by controlling the behaviour of these charge carriers through photocatalytic reactions. Moreover, the other exceptional properties of $\mathrm{TiO}_{2}$, such as its biological and chemical inertness, availability, environmental friendliness, low cost, and long-term stability against photo- and chemical corrosion, make it one of the best candidates for realizing light-mediated photochromism. Although there are various ways to fabricate heterogeneous $\mathrm{TiO}_{2}$ materials, due to its facile and economical route and advantages such as the dispersivity of nanocomposites and the ease of coating on non-conformal substrates, a solution-based approach is often used.

Here we developed the first ever solution processable $\mathrm{TiO}_{2} /$ $\mathrm{CuO}$ optical cavity that ingeniously manipulates light-matter interactions for enhanced chromogenic capabilities for rewritable imaging/printing/display purposes. It is noteworthy that this photocatalytic chromism phenomenon is highly dependent not only on the chemical constituents, but also on the structural design. Hence, the crucial aspects, such as light-matter interactions, accessibility and contact interfaces, must be taken into consideration in the construction of light stimulated phenomena. Accordingly, a hollow porous shell nanocomposite is designed to render high specific surface areas with a large number of active sites, a thin shell with reduced charge carrier diffusion length and improved accessibility through its porous framework. The nanocomposite not only possesses the aforementioned attributes, but its thin porous shell and cavity also favourably allow incident light to penetrate and display extensive local field enhanced areas. ${ }^{26}$ In regard to chemical constituents, $\mathrm{CuO}$ nanoparticles are specifically chosen as the counterpart of $\mathrm{TiO}_{2}$, owing to their fine-dispersivity, antimicrobial activity and cost effectiveness compared to other noble metals, and efficient photon capture and charge separation properties. ${ }^{27,28}$ The specific tailoring of $\mathrm{TiO}_{2} / \mathrm{CuO}$ in the nanoscale composition-structural aspects, leading to the above favourable properties, is expected to aid in enhancing photocatalytic activity, thereby boosting the light-mediated chromism performance.

Finally, a proof-of-concept of all-light induced reactions of the nanocomposite towards both applications in transmittance modulation and high-resolution ink-free rewritable patterning/ printing is validated. The nanocomposite possesses relatively high sensitivity, which results in a reasonable/short response time and high-resolution printing for fast and convenient visualization. The tunable intensity enables the construction of 3D images that exhibit persistency in image retention in the ambient environment, and warrants enough time for reading or temporary information storage. It also displays sufficiently fast switching under low-temperature heating for simple erasing, and good stability with multiple cycles for prolonged and repeated usage. The combination of a solution-processable, highly transparent noble metal-free inorganic nanocomposite with self-regulating light modulated properties can potentially meet society's increasing demand for integrated smart and energy-saving sustainable technology.

\section{Results and discussion}

Fig. 1a shows the process flow for synthesizing $\mathrm{TiO}_{2} / \mathrm{CuO}$ hollow nanocomposites. In the process, two different $\mathrm{TiO}_{2}$ nanostructures, namely $\mathrm{SiO}_{2} @ \mathrm{TiO}_{2}$ core-shell and hollow $\mathrm{TiO}_{2}$ structures, were synthesized by a sol-gel coating of a $\mathrm{TiO}_{2}$ shell on $\mathrm{SiO}_{2}$ template, followed by annealing to obtain crystalline $\mathrm{TiO}_{2}$ shells. Subsequently, the $\mathrm{SiO}_{2}$ template was removed completely to obtain the hollow $\mathrm{TiO}_{2}$ structures. The presynthesized $\mathrm{CuO}$ nanoparticles were loaded onto hollow $\mathrm{TiO}_{2}$ spheres with high uniformity and dispersivity. The finely dispersed $\mathrm{CuO} / \mathrm{TiO}_{2}$ system is highly favoured in photocatalysis, such as in photocatalytic hydrogen generation, degradation, reduction of $\mathrm{CO}_{2}$ or oxidation of volatile organic compounds,
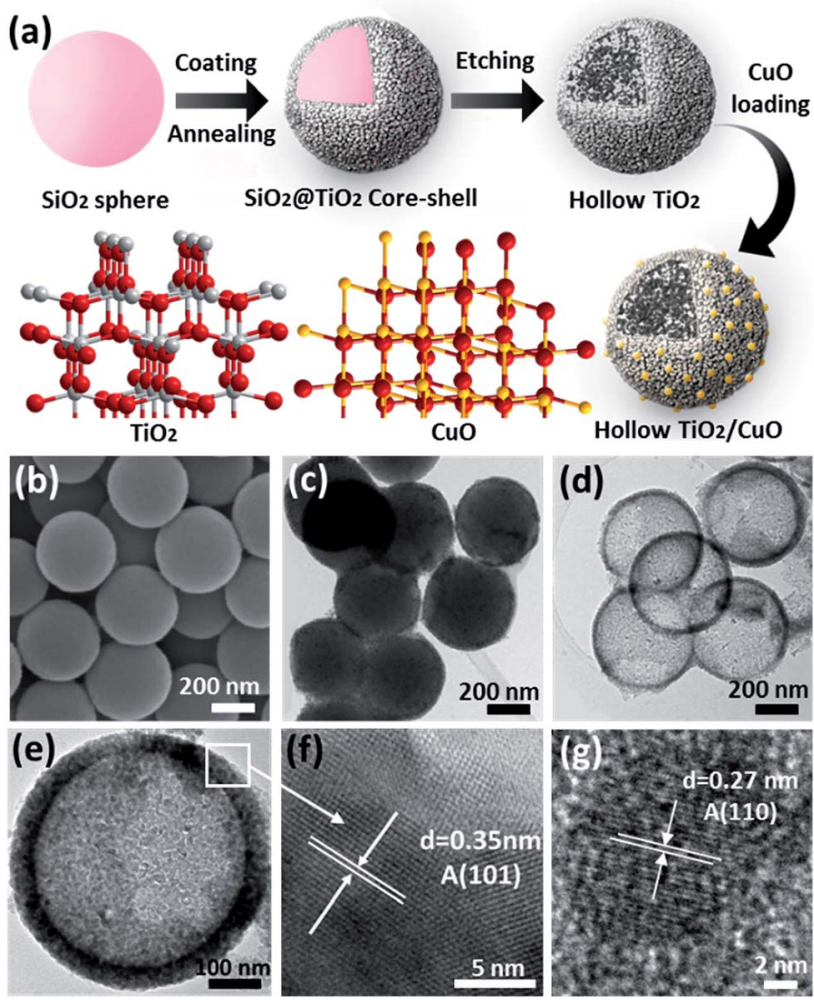

Fig. 1 (a) Schematic synthesis process for $\mathrm{SiO}_{2} \mathrm{CTiO}_{2}$ core-shell, hollow $\mathrm{TiO}_{2}$ and hollow $\mathrm{TiO}_{2} / \mathrm{CuO}$ structures. (b) $\mathrm{SEM}$ image of $\mathrm{SiO}_{2}$ nanospheres. TEM images of (c) $\mathrm{SiO}_{2} \mathrm{aTiO}_{2}$ core-shell and (d) hollow $\mathrm{TiO}_{2}$ nanospheres. (e) TEM image of the hollow $\mathrm{TiO}_{2} / \mathrm{CuO}$ nanocomposite. High-resolution TEM images of (f) hollow $\mathrm{TiO}_{2}$ and $(\mathrm{g}) \mathrm{CuO}$ nanoparticles in the $\mathrm{TiO}_{2} / \mathrm{CuO}$ nanocomposite. 
due to the efficient interparticle charge transfer process between the bonding of $\mathrm{CuO}$ and $\mathrm{TiO}_{2}$, for enhanced charge separation of photogenerated electron-hole pairs. ${ }^{29-32}$

The morphologies of the as-prepared samples were characterized by SEM (Fig. 1b and S1†) and TEM (Fig. 1c-e). Fig. 1b shows the spherical $\mathrm{SiO}_{2}$ template of a uniform size of $400 \mathrm{~nm}$. Fig. 1c shows the $\mathrm{SiO}_{2} @ \mathrm{TiO}_{2}$ core-shell nanosphere with a continuous $\mathrm{TiO}_{2}$ coating of $\sim 50 \mathrm{~nm}$. Fig. $\mathrm{S} 2 \dagger$ shows a bright field image of the $\mathrm{SiO}_{2} @ \mathrm{TiO}_{2}$ core-shell nanosphere and its respective elemental mappings. It can be seen that the $\mathrm{O}$ signal is found throughout the nanosphere, while the Si signal is located in the center portion with the Ti signal surrounding it. The hollow $\mathrm{TiO}_{2}$ structure was prepared by etching the $\mathrm{SiO}_{2}$ @$\mathrm{TiO}_{2}$ core-shell nanosphere in weak $\mathrm{NaOH}$ solution $(0.1 \mathrm{M})$ for $36 \mathrm{~h}$ to completely remove the $\mathrm{SiO}_{2}$ template (Fig. 1d). The XRD spectra of the $\mathrm{SiO}_{2} @ \mathrm{TiO}_{2}$ core-shell and hollow $\mathrm{TiO}_{2}$ nanospheres exhibit highly crystalline $\mathrm{TiO}_{2}$ anatase diffraction peaks, while no peak is observed for the non-crystalline $\mathrm{SiO}_{2}$ nanospheres (Fig. S3†). The TEM image (Fig. 1e) shows the $\mathrm{TiO}_{2} / \mathrm{CuO}$ hollow nanocomposite with a hollow cavity and a porous shell consisting of $\mathrm{TiO}_{2}$ nanoparticles. $\mathrm{CuO}$ nanoparticles were successfully loaded onto hollow $\mathrm{TiO}_{2}$ and evidently detected by EDX (Fig. S4a †). Moreover, CuO nanoparticles were finely dispersed on the $\mathrm{TiO}_{2}$ shell with an average size of $\sim 2 \mathrm{~nm}$ (Fig. $\mathrm{S} 4 \mathrm{~b} \dagger$ ). High-resolution TEM was then carried out at the marked locations. The selected area show a lattice fringe spacing of $0.35 \mathrm{~nm}$, attributed to the (101) plane of anatase $\mathrm{TiO}_{2}$ nanoparticles (Fig. 1f) and the (110) plane of $\mathrm{CuO}$ nanoparticles (Fig. 1g). These many small size heterojunctions formed between $\mathrm{TiO}_{2}$ and $\mathrm{CuO}$ play a crucial role in the efficient photocatalytic reduction of $\mathrm{CuO} .^{33-35}$

As the photochromic phenomenon is photocatalytically initiated by $\mathrm{TiO}_{2}$ nanocrystals generating electron-hole pairs under UV irradiation, the photogenerated electrons from $\mathrm{TiO}_{2}$ are transferred to $\mathrm{CuO}$ for reduction to $\mathrm{Cu}$, while the holes are scavenged by the sacrificial reagent. In order to achieve better photochromic performance in terms of response time, contrast and reversibility, a few factors need to be considered, including the light-harvesting capability for electron-hole pair generation, the optimal interface between $\mathrm{TiO}_{2}$ and $\mathrm{CuO}$ for interparticle charge transfer and accessibility of the reactant for efficiently removing holes. These factors associated with photo-stimulated reactions can be examined through photocatalysis, using the hydrogen generation rate as an indicator. The two different CuO-loaded $\mathrm{TiO}_{2}$ nanostructures, namely the $\mathrm{SiO}_{2} @ \mathrm{TiO}_{2} / \mathrm{CuO}$ core-shell and hollow $\mathrm{TiO}_{2} / \mathrm{CuO}$ structures, were evaluated for photocatalytic properties and compared against P25 $\mathrm{TiO}_{2} / \mathrm{CuO}$ nanoparticles. The same loading method has been carried out for all three samples with various loading amounts of $\mathrm{CuO}$ ranging from $3 \mathrm{wt} \%$ to $10 \mathrm{wt} \%$. Fig. S5† shows that both the $\mathrm{SiO}_{2} @ \mathrm{TiO}_{2}$ core-shell nanocomposites and hollow $\mathrm{TiO}_{2}$ nanospheres consistently outperformed P25 nanoparticles, even when $\mathrm{CuO}$ was absent, with $\sim 4$ and $\sim 10$ times enhancement of the photocatalytic $\mathrm{H}_{2}$ production rate, respectively. The photocatalytic performance of these materials is largely associated with structural features, such as surface area, cavity size, pore diameter and architecture, which can directly affect the reactant diffusion and light absorption capabilities that play important roles in photocatalysis. On the basis of heterogeneous catalytic reactivity being kinetically controlled by ion adsorption-diffusion in the pores of catalysts, the surface areas and pore sizes of these materials were investigated using BET. The $\mathrm{N}_{2}$ adsorption-desorption isotherm and the corresponding Barrett-Joyner-Halenda (BJH) pore size distributions (insets) are shown in Fig. S6.† Both the as-prepared samples have type IV isotherms with hysteresis loops that suggest the presence of mesopores of pore distribution $\sim 4-8 \mathrm{~nm}$ (Fig. S6†). ${ }^{36}$ This is consistent with TEM analysis, whereby the $\mathrm{TiO}_{2}$ shells are observed to be made up of aggregated highly dispersed $\mathrm{TiO}_{2}$ nanoparticles, with the interparticle voids forming the mesopores. Noticeably, the $\mathrm{TiO}_{2}$ hollow structure shows distinctively larger hysteresis loops, implying a higher absorption volume and hence larger BET surface area. This observation agrees with the fact that the hollow $\mathrm{TiO}_{2}$ structure has the largest surface area $\left(72 \mathrm{~m}^{2} \mathrm{~g}^{-1}\right)$, followed by the P25 nanoparticles $\left(43 \mathrm{~m}^{2} \mathrm{~g}^{-1}\right)$, while the coreshell structure has the lowest surface area of $30 \mathrm{~m}^{2} \mathrm{~g}^{-1}$. It is apparent that the porous hollow $\mathrm{TiO}_{2}$ structure has the highest surface area and an ideal mesoporous shell that renders numerous active sites, a highly accessible mass diffusion pathway, short charge migration distance and high viability to achieve more dispersed CuO loading that facilitates photoreactivity. ${ }^{21,22,26}$ When various amounts of $\mathrm{CuO}$ nanoparticles were loaded, the $\mathrm{H}_{2}$ production rate increased with the amount of $\mathrm{CuO}$ nanoparticles up to an optimal amount, where significant $\mathrm{H}_{2}$ production rates of $3475 \mu \mathrm{mol} \mathrm{g}{ }^{-1} \mathrm{~h}^{-1}, 1148 \mu \mathrm{mol} \mathrm{g}^{-1}$ $\mathrm{h}^{-1}$ and $930 \mu \mathrm{mol} \mathrm{g}{ }^{-1} \mathrm{~h}^{-1}$ were observed for the $\mathrm{SiO}_{2} @ \mathrm{TiO}_{2}$ core-shell nanocomposites, hollow $\mathrm{TiO}_{2}$ nanospheres and P25 nanoparticles, with $\mathrm{CuO}$ loading amounts of $5 \mathrm{wt} \%, 5 \mathrm{wt} \%$ and $3 \mathrm{wt} \%$, respectively (Fig. S5 $\dagger$ ). The remarkable enhancement is ascribed to the evenly-dispersed $\mathrm{CuO}$ co-catalyst nanoparticles well-interfaced with the $\mathrm{TiO}_{2}$ photocatalyst for efficient charge separation, which reduces the recombination rate. ${ }^{27}$ However, higher loading of $\mathrm{CuO}$ nanoparticles is seen to decrease the rate of $\mathrm{H}_{2}$ generation, possibly due to excessive loading, which leads to particle agglomeration, and consequently shielding of the photosensitive $\mathrm{TiO}_{2}$ surfaces. It is also suggested that overloading of the $\mathrm{CuO}$ co-catalyst may absorb photons, hence reducing the photoexcitation capacity of $\mathrm{TiO}_{2} \cdot{ }^{37}$ Not only does the $\mathrm{TiO}_{2} / \mathrm{CuO}$ hollow nanocomposite exhibit a remarkable photocatalytic response, it also shows superior stability under UV light. The cycling of photocatalysis was conducted for the 5 wt\% CuO-loaded $\mathrm{TiO}_{2}$ nanocomposite (Fig. S7 $\dagger$ ), which exhibits a stable hydrogen generation rate of $3387 \mu \mathrm{mol} \mathrm{g}^{-1} \mathrm{~h}^{-1}$ with a variance of $2 \%$. This ensures prolonged usability of the sample even under strong outdoor light.

As the enhancement in photocatalytic hydrogen production is disproportional to the increase of surface area, this suggests that surface area is not the only factor that affects the photocatalytic hydrogen production rate. The optical properties of these two structures, namely the $\mathrm{SiO}_{2} @ \mathrm{TiO}_{2}$ core-shell and hollow $\mathrm{TiO}_{2}$ structures, were studied. The $\mathrm{SiO}_{2}$-based core-shell structure has been demonstrated as a successful candidate to improve various optical properties, such as imaging, focusing, and optical nonlinearity. ${ }^{38,39}$ However, for various applications 
that require high light-matter interactions, it is possible to design novel structures with better performances than that of the $\mathrm{SiO}_{2}$-based core-shell structure. The key mechanism for the $\mathrm{SiO}_{2}$-based core-shell structure is the focusing effect induced by the refraction of the $\mathrm{SiO}_{2}$ particle lens. In this paper, the proposed $\mathrm{TiO}_{2}$ hollow structure has a similar focusing effect and better light-matter interactions. This hollow shell structure with the high refractive index $\mathrm{TiO}_{2}$ material induces light refraction, leading to the focusing effect (Fig. 2a). To better understand the optical performance of the hollow $\mathrm{TiO}_{2}$ structure, we conducted Finite-Difference Time-Domain (FDTD) simulations with Lumerical software (the details for the simulation parameters can be found in the experimental section). As shown in Fig. 2b and c, both the $\mathrm{SiO}_{2} @ \mathrm{TiO}_{2}$ core-shell and hollow $\mathrm{TiO}_{2}$ structures induce a focusing effect due to refraction by the spherical shape. However, the focusing effects induced by these two systems are not identical. For the $\mathrm{SiO}_{2} @ \mathrm{TiO}_{2}$ coreshell structure, the silica core serves as a particle lens. This particle lens focuses the light into a relatively small volume to create a high local field intensity. For the hollow $\mathrm{TiO}_{2}$ structure, due to the lack of particle lens, the light is not restricted to a small area. Instead, the local field enhanced area extends across a large region. Internally, it is found in the simulation that the hollow $\mathrm{TiO}_{2}$ system has a lower transmittance than the $\mathrm{SiO}_{2} @ \mathrm{TiO}_{2}$ core-shell system (simulation method in ESI $\dagger$ ). From the distribution of the light energy (Fig. 2b), it is obvious that the $\mathrm{SiO}_{2} @ \mathrm{TiO}_{2}$ core-shell system focuses the light better.
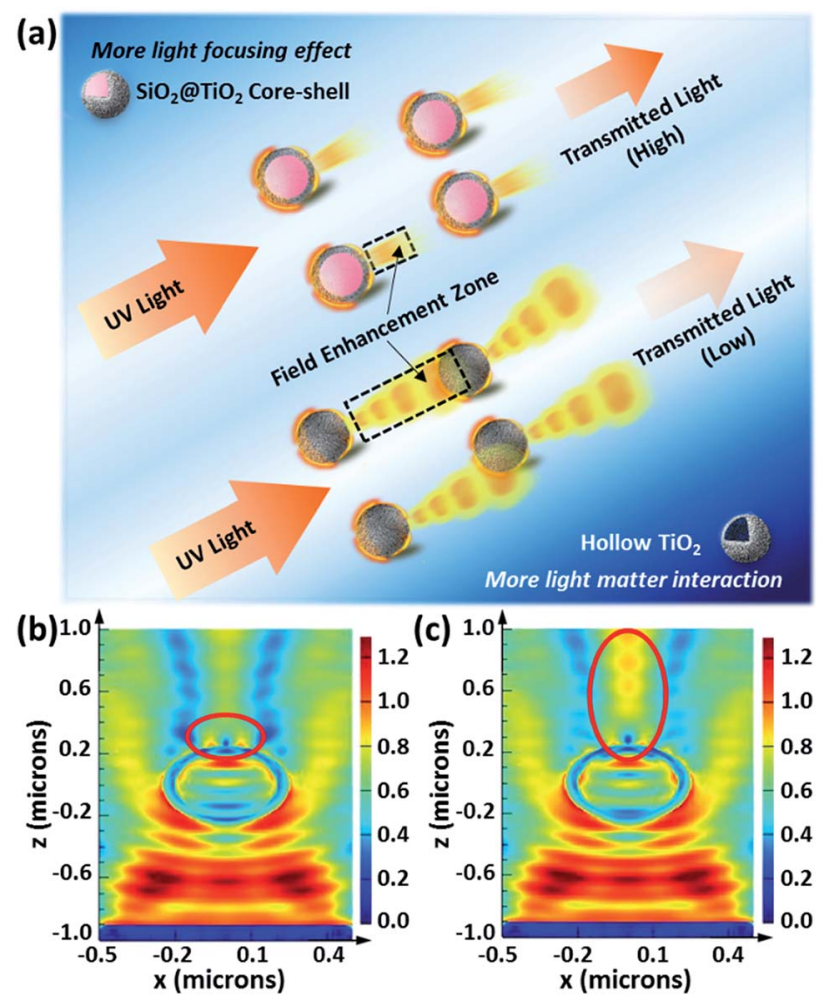

Fig. 2 (a) Schematic to demonstrate the differences between the $\mathrm{SiO}_{2} \mathrm{aTiO}_{2}$ core-shell and hollow $\mathrm{TiO}_{2}$ nanostructures. The light $\mathrm{E}-$ field distribution of the (b) $\mathrm{SiO}_{2} \mathrm{CTiO}_{2}$ core-shell and (c) hollow $\mathrm{TiO}_{2}$ nanostructures.
In other words, most of the light transmits through the hybrid system in the central region, as shown in Fig. 2b. In the hollow $\mathrm{TiO}_{2}$ system, the lack of focusing leads to better light-matter interactions on the $\mathrm{TiO}_{2}$ shell. More local field enhanced areas can be found near the $\mathrm{TiO}_{2}$ shell (red circles in Fig. $2 \mathrm{~b}$ and c). As $\mathrm{TiO}_{2}$ is the material that absorbs the light, less light can transmit through the hollow $\mathrm{TiO}_{2}$ system compared to the $\mathrm{SiO}_{2} @ \mathrm{TiO}_{2}$ core-shell system. Essentially, these external and internal effects make the hollow $\mathrm{TiO}_{2}$ structure a more favorable platform for many photo-chemical reactions, as confirmed by the following experiments.

From the UV-vis spectra presented in Fig. $3 \mathrm{a}, \mathrm{TiO}_{2} / \mathrm{CuO}$ hollow nanospheres show distinct light absorption enhancement in the UV region compared to $\mathrm{SiO}_{2} @ \mathrm{TiO}_{2} / \mathrm{CuO}$ core-shell nanocomposites and $\mathrm{P} 25 / \mathrm{CuO}$ nanoparticles. This is most likely caused by the stronger light-matter interactions of the hollow $\mathrm{TiO}_{2}$ nanostructure, based on the simulation results that have been discussed earlier. The light absorption of this light focusing scheme is comparatively lower than that of the hollow structural configurations, as seen from the simulation results (additional simulation results, Sections $1 \& 2$ in ESI $\dagger$ ). Moreover, the presence of the $\mathrm{SiO}_{2}$ core directly in contact with the $\mathrm{TiO}_{2}$ shell greatly reduces the exposed surface area, resulting in the lowest accessible active surface sites. The P25/CuO nanoparticles have the lowest absorption, due to light passing through the particles directly without any light focusing effect. ${ }^{26}$ Hence, based on the aforementioned reasons, the hollow $\mathrm{TiO}_{2} /$ $\mathrm{CuO}$ nanospheres outperform both the $\mathrm{SiO}_{2} @ \mathrm{TiO}_{2} / \mathrm{CuO}$ coreshell structure and $\mathrm{P} 25 / \mathrm{CuO}$ nanoparticles for both light absorption capability and reactant diffusion properties, which can be translated into better photochromic performance.
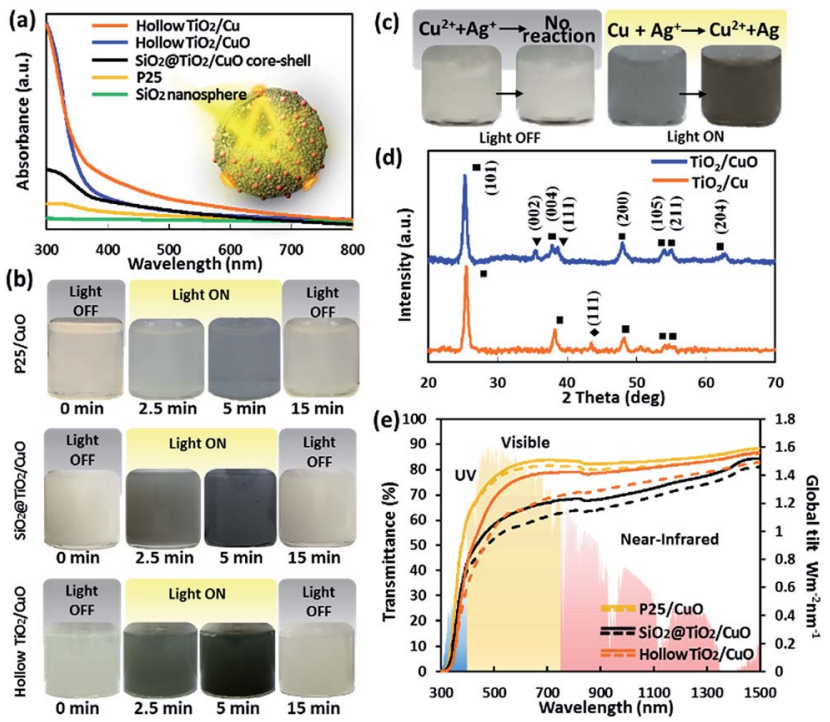

Fig. 3 (a) Absorption spectra of $\mathrm{SiO}_{2}, \mathrm{P} 25 / \mathrm{CuO}$ nanoparticle, $\mathrm{SiO}_{2} \mathrm{a}$ $\mathrm{TiO}_{2} / \mathrm{CuO}$ core-shell, hollow $\mathrm{TiO}_{2} / \mathrm{CuO}$ and hollow $\mathrm{TiO}_{2} / \mathrm{Cu}$ structures. (b) Digital images of the photochromic effect of P25/CuO nanoparticles, $\mathrm{SiO}_{2} \mathrm{CTiO}_{2} / \mathrm{CuO}$ core-shell and $\mathrm{TiO}_{2} / \mathrm{CuO}$ hollow nanocomposites in solution. (c) Visual validation of $\mathrm{Cu}$ formation with $\mathrm{AgNO}_{3}$ addition. (d) XRD spectra before and after light irradiation. (e) Transmittance spectra of various nanocomposites coated on glass. 
The samples with the optimal $\mathrm{CuO}$ loading amount were tested for their sensitivity to UV light $(365 \mathrm{~nm})$ to measure the rate of the photochromic response. After a few minutes' exposure, the white coloured solution turned light grey, and subsequent illumination resulted in a darker grey solution. Among the three samples, the hollow $\mathrm{TiO}_{2} / \mathrm{CuO}$ and $\mathrm{SiO}_{2} @ \mathrm{TiO}_{2} / \mathrm{CuO}$ core-shell structures had significantly fast response times with only $2.5 \mathrm{~min}$ irradiation, while the colour change of the P25/ $\mathrm{CuO}$ nanoparticles was not obvious with the same irradiation time, as shown in Fig. 3b. The reversal of the colour back to its initial state can be observed $10 \mathrm{~min}$ after turning off the light. The photochromic reversibility is derived from two processes, i.e. the photo-reduction of $\mathrm{CuO}$ to $\mathrm{Cu}$ metal, ${ }^{\mathbf{1 4 , 4 0}}$ which turns the colour of solution dark grey due to the presence of the Cu metal, and the oxidation of $\mathrm{Cu}$ metal back to $\mathrm{CuO}$ in the presence of oxygen. ${ }^{41}$ The presence of $\mathrm{Cu}$ after irradiation can be confirmed by the redox reaction with the addition of $\mathrm{AgNO}_{3}$ (Fig. 3c). $\mathrm{AgNO}_{3}$ acts as an oxidising agent, while $\mathrm{Cu}$ acts as the reducing agent. Hence, the $\mathrm{Ag}^{+}$ions are reduced to $\mathrm{Ag}$ particles (eqn (1)), while $\mathrm{Cu}$ is oxidised to $\mathrm{Cu}^{2+}$ (eqn (2)). ${ }^{42}$ The end product is the formation of $\mathrm{Cu}^{2+}$ ions and $\mathrm{Ag}$ metal precipitate (eqn (3)).

$$
\begin{gathered}
2 \mathrm{Ag}(\mathrm{s}) \rightarrow 2 \mathrm{Ag}^{+}(\mathrm{aq})+2 \mathrm{e}^{-} \text {[oxidation] } \\
\mathrm{Cu}^{2+}+2 \mathrm{e}^{-} \rightarrow \mathrm{Cu}(\mathrm{s}) \text { [reduction] } \\
\mathrm{Cu}(\mathrm{s})+2 \mathrm{Ag}^{+}(\mathrm{aq}) \rightarrow \mathrm{Cu}^{2+}(\mathrm{aq})+2 \mathrm{Ag}(\mathrm{s})
\end{gathered}
$$

$0.1 \mathrm{M} \mathrm{AgNO}_{3}$ solution was added separately to $\mathrm{TiO}_{2} / \mathrm{CuO}$ hollow nanocomposite solutions with and without UV light exposure. No colour change is observed in the absence of UV, since $\mathrm{CuO}$ is not photoreduced to $\mathrm{Cu}$ metal and does not react with $\mathrm{AgNO}_{3}$ (Fig. 3c). In contrast, a colour change from white to grey is observed with light irradiation, and upon addition of $\mathrm{AgNO}_{3}$ solution, a further colour change from grey to brownishgrey is noted (Fig. 3c). This indicates the precipitation of $\mathrm{Ag}$ particles and hence confirms the formation of $\mathrm{Cu}$ metal with UV light exposure. XRD was carried out to verify the reduction of $\mathrm{CuO}$ to $\mathrm{Cu}$ metal. Both samples exhibit a strong anatase $\mathrm{TiO}_{2}$ peak before and after exposure to UV light (Fig. 3d), which affirms that $\mathrm{TiO}_{2}$ remains unchanged and the observed colour change can be solely attributed to the transformation of $\mathrm{CuO}$. Two additional peaks at $35.4^{\circ}$ and $38.8^{\circ}$ are observed for the $\mathrm{TiO}_{2} / \mathrm{CuO}$ sample without UV light exposure, which correspond to the (002) and (111) planes of $\mathrm{CuO}$, respectively. Conversely, a peak at $43.5^{\circ}$, corresponding to the (111) plane of $\mathrm{Cu}$ metal, is observed for the sample that was subjected to UV exposure. This evidently reveals the complete transformation of $\mathrm{CuO}$ to $\mathrm{Cu}$ metal under UV light irradiation. The light absorption properties of $\mathrm{TiO}_{2} / \mathrm{CuO}$ and $\mathrm{TiO}_{2} /$ $\mathrm{Cu}$ were investigated by UV-vis spectroscopy. From the UV-vis spectra presented in Fig. 3a, the $\mathrm{TiO}_{2} / \mathrm{Cu}$ hollow nanocomposite shows light absorption enhancement compared to the $\mathrm{TiO}_{2} / \mathrm{CuO}$ hollow nanocomposite. The excited electrons can migrate to the valence band of the $\mathrm{CuO}$ nanoparticles, thus enhancing the absorption centered at $\sim 450 \mathrm{~nm}$. The electrons are also able to reduce the $\mathrm{Cu}^{2+}$ ions, thus creating the absorption tail in the 500$600 \mathrm{~nm}$ range due to the plasmonic absorption of the $\mathrm{Cu}$ metal. ${ }^{\mathbf{1 4 4 3}}$
With the success of the solution-based photochromism demonstration, attempts were made to formulate a coating of $\mathrm{TiO}_{2} / \mathrm{CuO}$ hollow nanocomposites on various rigid/flexible substrates. The photochromic properties of the $\mathrm{SiO}_{2} @ \mathrm{TiO}_{2} /$ $\mathrm{CuO}$ core-shell, hollow $\mathrm{TiO}_{2} / \mathrm{CuO}$ and $\mathrm{P} 25 / \mathrm{CuO}$ nanoparticle structures loaded with an optimal amount of $\mathrm{CuO}$ nanoparticles coated on a glass substrate were studied in the UV-vis-NIR range by measuring their respective transmittance before (solid line) and after (dotted line) UV light illumination (Fig. 3e). The transmitted efficiency (TE) and shielding efficiency (SE) of different wavelengths (UV: $300-400 \mathrm{~nm}$, vis: $400-750 \mathrm{~nm}$ and NIR: 750-1500 $\mathrm{nm}$ ) can be derived from the transmittance spectra and standard solar spectrum (ESI Table $2 \dagger) .{ }^{\mathbf{4 4}}$ Comparing the samples of CuO-loaded $\mathrm{P} 25, \mathrm{SiO}_{2} @ \mathrm{TiO}_{2}$ coreshell and hollow $\mathrm{TiO}_{2}$ after UV illumination, the SE in UV, visible and NIR light region increases from 63.5, 22.8, 18.8\% $(\mathrm{P} 25 / \mathrm{CuO})$ and $76.8,44.7,32.9 \%\left(\mathrm{SiO}_{2} @ \mathrm{TiO}_{2} / \mathrm{CuO}\right.$ core-shell $)$ to 83.3, 40.2, 26.3\% (hollow $\mathrm{TiO}_{2} / \mathrm{CuO}$ ), respectively. This evidently shows that the hollow $\mathrm{TiO}_{2}$ structure has the highest solar shielding across the UV-vis-NIR range. This shielding effect, along with sufficient visible light transmittance, can be of use in variable optical transmission materials, such as photochromic camera filters or photochromic lenses, ${ }^{45}$ and also in energyefficient building applications, such as smart windows or glass facades. ${ }^{46}$ Hollow $\mathrm{TiO}_{2} / \mathrm{CuO}$ nanocomposites with a fast photochromic response time, high solar shielding and excellent stability under UV light were demonstrated for chromogenic erasable patterning/printing on both rigid and flexible substrates with tunable intensity, excellent legibility and high resolution. A schematic diagram of the patterning setup is shown in Fig. 4a. Photomasks with different printing patterns were used with a substrate coated with a thin layer of $\mathrm{TiO}_{2} / \mathrm{CuO}$ hollow nanocomposites. Fig. S10 $\uparrow$ shows the nanocomposite coating of $\sim 1 \mu \mathrm{m}$ thickness on glass that exhibits a reasonably high optical clarity. The hollow $\mathrm{TiO}_{2} / \mathrm{CuO}$-coated glass with its respective SEM cross-section and top views are shown in Fig. S10 $\dagger$ as well. The uniform coating on light-weight and flexible PET (Fig. 4b) offers a contour shape useful for conformable and portable displays and photodetectors/sensors, etc. $^{45}$ The light illumination intensity can be tuned for fine tailoring of chromogenic contrasts, as shown by the printed colors with transmittance measurements (Fig. 4c). Meanwhile, selective control of chromogenic contrast without direct contact with the surface of the coating can be demonstrated, making it remotely controllable. Accordingly, various projected pattern masks were used to realize selective photochromogenic transparent displays (Fig. 4d). Furthermore, the coating is extended to a rewritable display capable of projecting $3 \mathrm{D}$ patterns to establish the capacity of the dynamic display. The write-erase repetitions as well as assorted switchable contrasts of different faces of the same 3D box pattern are validated (Fig. 4e). The reversibility of the chromogenic coating makes it an ideal erasable-writable medium. Finally, the high-resolution pattern is demonstrated on a rewritable display (Fig. $4 \mathrm{f}$ and g). Notably, the pattern of $\sim 100-200 \mu \mathrm{m}$ can be resolved and conspicuously observed under high magnification. Micro- to nano-scale patterning of Merlion, an iconic landmark of Singapore, was 
(a)

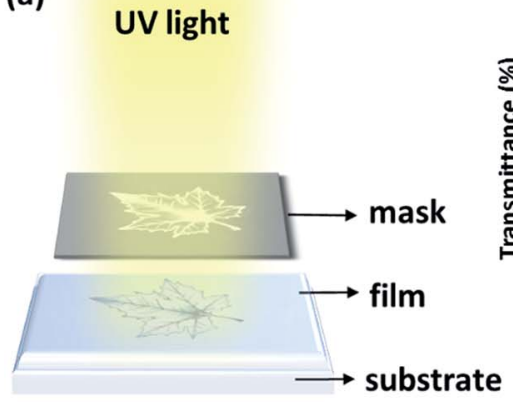

(b)

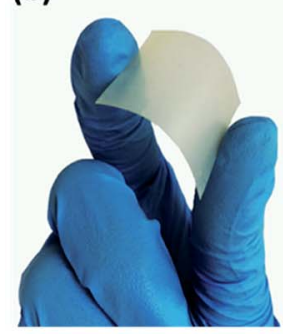

(d)

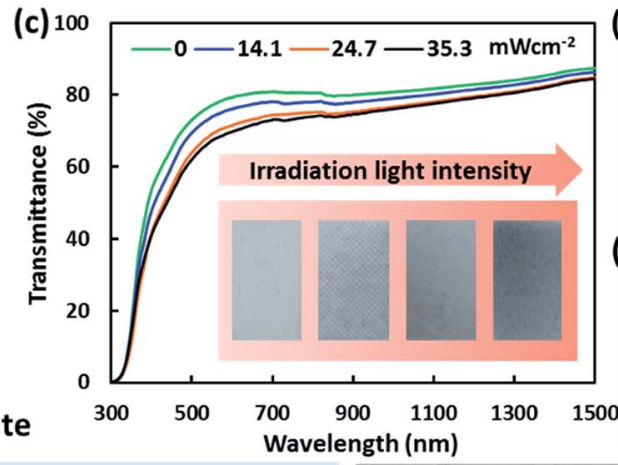

(g)

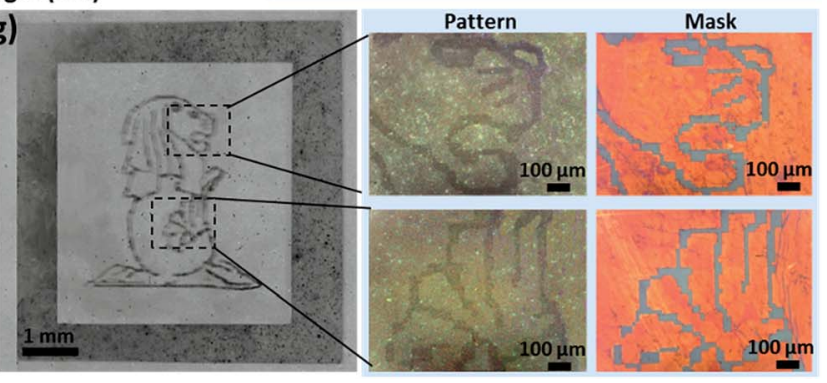

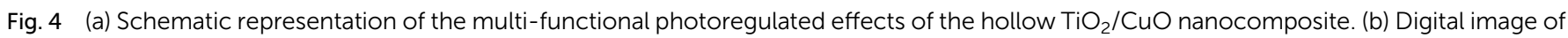
the $\mathrm{TiO}_{2} / \mathrm{CuO}$ coating on flexible PET. (c) Transmittance spectra and digital photos of hollow $\mathrm{TiO}_{2} / \mathrm{CuO}$ on the glass substrate with different light irradiation intensities. Demonstrations of (d) a variety of chromogenic patterns, (e) write-erase repetitions with assorted switchable contrasts and ( $f$ and $g$ ) high-resolution patterning.

also demonstrated, with the highest resolution of $\sim 20 \mu \mathrm{m}$ observed under the microscope as shown in Fig. $4 \mathrm{~g}$ and $\mathrm{S} 11, \dagger$ with both the printed images and the mask used. The important attributes of a photochromic display are that the pattern and information are exhibited by reflecting the surrounding light (of a non-emissive nature), that it is easy on the eye, ink-free, rewritable and can be adopted even in bright outdoor space. In this regard, the outdoor photochromic projection can make use of natural sunlight for dynamic displays that change in accordance with the projected pattern/information. Moreover, such a display that effectively responds to a light stimulus, unlike other active solar devices, is easy and inexpensive to implement and maintain since it does not involve any mechanical and electrical components.

The sensitivity, reversibility and repeatability of the $\mathrm{TiO}_{2} /$ CuO hollow nanocomposite coating were studied. Firstly, the sensitivity of the as-prepared materials was tested using glass as the substrate. Light illumination duration and intensity can be varied and controlled to have multiple chromogenic contrasts alongside selective patterning on the substrate. The transmittance measurements with different light intensities were demonstrated earlier, in Fig. 4c. Here, the duration of illumination under UV light was examined and the results are shown in Fig. S12. $\dagger$ The response time was $\sim 1 \mathrm{~min}$ in order to obtain a legible print with a font size of 10 , and prolonged illumination enhanced both the intensity and the lifetime of the print. In addition, the writing process under common solar irradiation was also demonstrated with a longer printing time of $4.5 \mathrm{~min}$ to obtain similar contrast to that obtained with 1 min UV irradiation (Fig. S13†). The information printed under $2 \mathrm{~min}$ UV illumination can be retained for 20 days under ambient conditions and standard office brightness (500 lx), as shown in Fig. S14, $\uparrow$ which allows its practical use for fabricating rewritable media with long-lasting legibility. The time taken to revert the colour change is far longer than what has been previously reported. ${ }^{17,22}$ Secondly, the photoreversible chromogenic function is validated. The color is very slow to revert under ambient conditions, however it can be sufficiently fast when lowtemperature heating is applied. The printed information can be erased within $10 \mathrm{~min}, 5 \mathrm{~min}$ and 4 min under different heating conditions of 85, 95 and $105{ }^{\circ} \mathrm{C}$, respectively, with less than $1 \%$ variance in transmittance compared with an initial stage at $600 \mathrm{~nm}$ (Fig. S15 ${ }^{\dagger}$ ). The transmittance at $600 \mathrm{~nm}$ with writing and erasing (at $95{ }^{\circ} \mathrm{C}$ ) time is presented in Fig. 5a, and the respective images are shown in Fig. $5 \mathrm{~b}$ and c. Thirdly, the stability and repeatability of the material were examined. The transmittance of the $\mathrm{TiO}_{2} / \mathrm{CuO}$ hollow nanocomposites was measured for ten repetitive reduction-oxidation cycles, as shown in Fig. $5 \mathrm{~d}$. The photochromic effect is highly reversible as the transmittance reverts to its pristine state across the UV-visNIR range for all the cycles. The specific transmittances at wavelengths of 600 and $1000 \mathrm{~nm}$ were measured in relation to the transparency and photothermal characteristics (Fig. 5e). The average initial transmittances at 600 and $1000 \mathrm{~nm}$ were measured to be $\sim 78$ and $\sim 80 \%$, respectively. After irradiation with UV light, the average transmittances dropped to $\sim 71$ and $\sim 75 \%$, which indicate a $\sim 9$ and $\sim 6 \%$ drop in the visible and NIR wavelengths, respectively. The demonstration of repeated cycles establishes the reversibility of the photochromic effect and the stability of the hollow $\mathrm{TiO}_{2} / \mathrm{CuO}$ nanocomposite. It was shown that the hollow $\mathrm{TiO}_{2}$ nanocomposite can exhibit selfregulating reversible photochromism for at least 25 cycles 

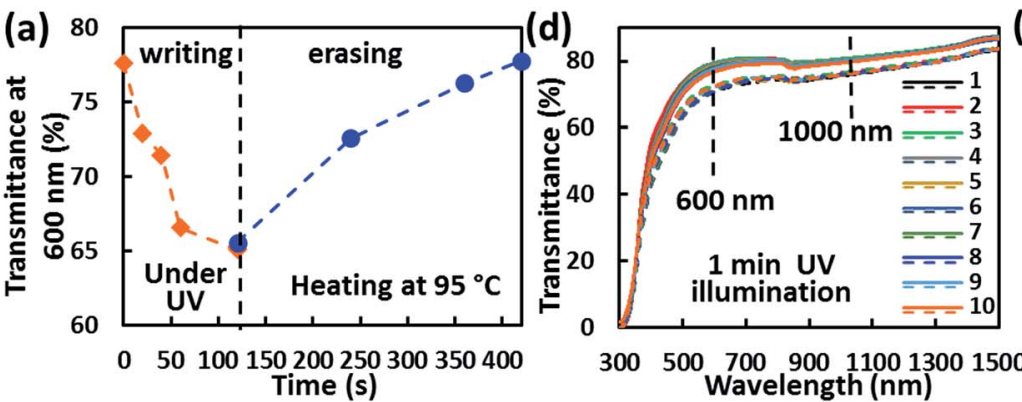

(b)

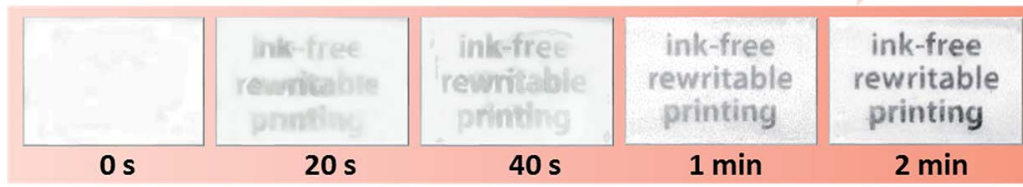

(c)

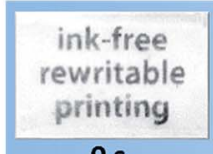

$0 \mathrm{~s}$
Erasing under heating at $95^{\circ} \mathrm{C}$

Writing under UV light illumination

ink-free

printing

$1 \mathrm{~min}$

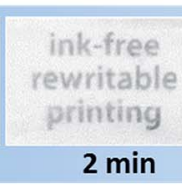

rewritable

$4 \mathrm{~min}$

$5 \mathrm{~min}$
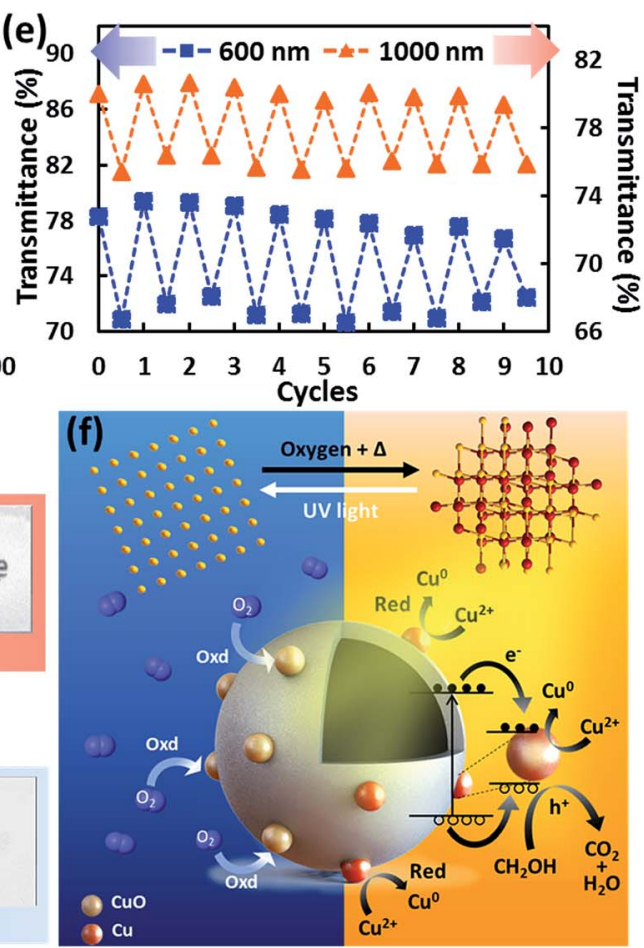

Fig. 5 (a) Transmittance at $600 \mathrm{~nm}$ of the hollow $\mathrm{TiO}_{2} / \mathrm{CuO}$ coating on glass with writing and erasing processes. Digital photos of the hollow $\mathrm{TiO}_{2} / \mathrm{CuO}$ coating on glass with (b) writing and (c) erasing processes over time. (d) Transmittance modulation cycles of oxidation (solid lines) and reduction (dotted lines). (e) The switchable photochromogenic transmittance at $600 \mathrm{~nm}$ and $1000 \mathrm{~nm}$. (f) Mechanism of reversible photochromic coupled photocatalysis phenomena.

(Fig. S16 $\dagger$ ). Fig. $5 f$ shows the proposed mechanism for the light stimulus-responsive reaction of the hollow $\mathrm{TiO}_{2} / \mathrm{CuO}$ nanocomposite. When light illuminates on the hollow $\mathrm{TiO}_{2} / \mathrm{CuO}$ nanocomposite, electron-hole pairs are generated within $\mathrm{TiO}_{2}$. Since $\mathrm{CuO}$ is in direct contact with the $\mathrm{TiO}_{2}$ shell, and the energy potential of $\mathrm{CuO}$ lies slightly below that of $\mathrm{TiO}_{2}$, migration of the photogenerated electrons from the conduction band of $\mathrm{TiO}_{2}$ to $\mathrm{CuO}$ can effectively take place, while the holes are scavenged by the sacrificial reagent (which is menthol in this case) to prevent electron-hole pair recombination. ${ }^{47}$ This results in efficient charge transfer of photogenerated electrons from $\mathrm{TiO}_{2}$ to $\mathrm{CuO},{ }^{\mathbf{4 8 , 4 9}}$ and meanwhile these transferred electrons react with $\mathrm{CuO}$, which undergoes a reduction process to produce $\mathrm{Cu}^{\mathbf{5 0}}$ This reduction process, which is initiated by the photocatalytic reaction in $\mathrm{TiO}_{2}$, causes the colour change of the substrate from white $\left(\mathrm{TiO}_{2} / \mathrm{CuO}\right)$ to dark grey $\left(\mathrm{TiO}_{2} / \mathrm{Cu}\right)$ under light irradiation. To revert the colour to white, the substrate is left in ambient air and $\mathrm{Cu}$ can easily react with $\mathrm{O}_{2}$ to form $\mathrm{CuO}$ again, while heating the substrate will accelerate the oxidation process. Generally, nanoparticles are metastable owing to their relatively high surface area, causing them to be readily oxidized in oxygen. ${ }^{41,51}$ This mechanism provides the viability for ink-free rewritable printing with a high resolution and long lifetime, as well as reasonably fast erasing upon the simple low-temperature heating process.

\section{Conclusions}

We have designed and demonstrated a solution-based hollow $\mathrm{TiO}_{2} / \mathrm{CuO}$ nanocomposite which is capable of displaying both photochromism and catalysis effects under solar irradiation. The $\mathrm{TiO}_{2} / \mathrm{CuO}$ hollow nanocomposite outperforms the $\mathrm{SiO}_{2}$ @$\mathrm{TiO}_{2}$ yolk-shell and core-shell structures. The enhanced light harvesting and reactant diffusion properties of the $\mathrm{TiO}_{2} / \mathrm{CuO}$ hollow nanocomposite are attributed to the designed structural parameters of highly accessible numerous active sites in the mesoporous shell, reduced charge carrier diffusion length in the thin shell, homogeneous heterostructures for enhanced molecular interfacial interactions and optical fields for photon-matter interactions. The nanocomposite is proven to effectively utilize light irradiation for photochromism, which is manifested in variable phototransmittance and ink-free high-resolution rewritable printing/displays. Hence, such an innovative noble metal-free inorganic nanocomposite with multifunctional light modulated chromogenic coupled catalysis properties can deliver promising light-stimulus smart technology solutions.

\section{Acknowledgements}

This work is supported by the National Research Foundation Singapore, Ministry of National Development (MND), R-263000-C22-277.

\section{References}

1 B. W. Faughnan, D. L. Staebler and Z. J. Kiss, Applied Solid State Science, New York: Academic Press, New York, 1971.

2 K. V. Wong and R. Chan, J. Energy Resour. Technol., 2013, 136, 012002. 
3 T. He and J. Yao, Prog. Mater. Sci., 2006, 51, 810-879.

4 G. Wirnsberger, B. J. Scott, B. F. Chmelka and G. D. Stucky, Adv. Mater., 2000, 12, 1450-1454.

5 W. Wang, N. Xie, L. He and Y. Yin, Nat. Commun., 2014, 5, 5459.

6 X. Du, T. Li, L. Li, Z. Zhang and T. Wu, J. Mater. Chem. C, 2015, 3, 3542-3546.

7 R. Klajn, P. J. Wesson, K. J. M. Bishop and B. A. Grzybowski, Angew. Chem., Int. Ed., 2009, 48, 7035-7039.

8 I. Kawashima, H. Takahashi, S. Hirano and R. Matsushima, J. Soc. Inf. Disp., 2004, 12, 81-85.

9 R. A. Evans, T. L. Hanley, M. A. Skidmore, T. P. Davis, G. K. Such, L. H. Yee, G. E. Ball and D. A. Lewis, Nat. Mater., 2005, 4, 249-253.

10 L. Sheng, M. Li, S. Zhu, H. Li, G. Xi, Y.-G. Li, Y. Wang, Q. Li, S. Liang, K. Zhong and S. X.-A. Zhang, Nat. Commun., 2014, 5, 3044.

11 B. Garai, A. Mallick and R. Banerjee, Chem. Sci., 2016, 7, 2195-2200.

12 J. Su, T. Fukaminato, J.-P. Placial, T. Onodera, R. Suzuki, H. Oikawa, A. Brosseau, F. Brisset, R. Pansu, K. Nakatani and R. Métivier, Angew. Chem., 2016, 128, 3726-3730.

13 S.-J. Lim, B.-K. An, S. D. Jung, M.-A. Chung and S. Y. Park, Angew. Chem., 2004, 116, 6506-6510.

14 D. M. Tobaldi, N. Rozman, M. Leoni, M. P. Seabra, A. S. Škapin, R. C. Pullar and J. A. Labrincha, J. Phys. Chem. C, 2015, 119, 23658-23668.

15 N. Crespo-Monteiro, N. Destouches, L. Bois, F. Chassagneux, S. Reynaud and T. Fournel, Adv. Mater., 2010, 22, 3166-3170.

16 Q. Qiao, X. Zhang, Z. Lu, L. Wang, Y. Liu, X. Zhu and J. Li, Appl. Phys. Lett., 2009, 94, 074104.

17 K. Naoi, Y. Ohko and T. Tatsuma, Chem. Commun., 2005, 1288-1290, DOI: 10.1039/b416139d.

18 E. Kazuma and T. Tatsuma, Chem. Commun., 2012, 48, 17331735.

19 K. Kawahara, K. Suzuki, Y. Ohko and T. Tatsuma, Phys. Chem. Chem. Phys., 2005, 7, 3851-3855.

20 R. Han, X. Zhang, L. Wang, R. Dai and Y. Liu, Appl. Phys. Lett., 2011, 98, 221905.

21 N. Crespo-Monteiro, N. Destouches, L. Nadar, S. Reynaud, F. Vocanson and J. Y. Michalon, Appl. Phys. Lett., 2011, 99, 173106.

22 Y. Ohko, T. Tatsuma, T. Fujii, K. Naoi, C. Niwa, Y. Kubota and A. Fujishima, Nat. Mater., 2003, 2, 29-31.

23 Z. W. Seh, S. Liu, M. Low, S.-Y. Zhang, Z. Liu, A. Mlayah and M.-Y. Han, Adv. Mater., 2012, 24, 2310-2314.

24 M. Gao, C. K. N. Peh, W. L. Ong and G. W. Ho, RSC Adv., 2013, 3, 13169-13177.

25 M. Gao, C. K. N. Peh, Y. Pan, Q.-H. Xu and G. W. Ho, Nanoscale, 2014, 6, 12655-12664.

26 M. Gao, L. Zhu, W. L. Ong, J. Wang and G. W. Ho, Catal. Sci. Technol., 2015, 5, 4703-4726.
27 C. K. N. Peh, M. Gao and G. W. Ho, J. Mater. Chem. A, 2015, 3, 19360-19367.

28 L. Zhu, M. Hong and G. W. Ho, Nano Energy, 2015, 11, 28-37.

29 K. Lalitha, G. Sadanandam, V. D. Kumari, M. Subrahmanyam, B. Sreedhar and N. Y. Hebalkar, J. Phys. Chem. C, 2010, 114, 22181-22189.

30 J. Bandara, C. P. K. Udawatta and C. S. K. Rajapakse, Photochem. Photobiol. Sci., 2005, 4, 857-861.

31 D. Barreca, G. Carraro, V. Gombac, A. Gasparotto, C. Maccato, P. Fornasiero and E. Tondello, Adv. Funct. Mater., 2011, 21, 2611-2623.

32 L. Li, W. Li, A. Ji, Z. Wang, C. Zhu, L. Zhang, J. Yang and L.-F. Mao, Phys. Chem. Chem. Phys., 2015, 17, 17880-17886.

33 I. Mondal and U. Pal, Phys. Chem. Chem. Phys., 2016, 18, 4780-4788.

34 G. D. Moon, J. B. Joo, I. Lee and Y. Yin, Nanoscale, 2014, 6, 12002-12008.

35 X.-J. Lv, S.-X. Zhou, C. Zhang, H.-X. Chang, Y. Chen and W.-F. Fu, J. Mater. Chem., 2012, 22, 18542-18549.

36 S. Storck, H. Bretinger and W. F. Maier, Appl. Catal., A, 1998, 174, 137-146.

37 G. Li, N. M. Dimitrijevic, L. Chen, T. Rajh and K. A. Gray, J. Phys. Chem. C, 2008, 112, 19040-19044.

38 M. Wu, R. Chen, J. Soh, Y. Shen, L. Jiao, J. Wu, X. Chen, R. Ji and M. Hong, Sci. Rep., 2016, 6, 31637.

39 Z. Du, L. Chen, T.-S. Kao, M. Wu and M. Hong, Beilstein J. Nanotechnol., 2015, 6, 1199-1204.

$40 \mathrm{~S} . \mathrm{Xu}, \mathrm{J} . \mathrm{Ng}, \mathrm{A} . \mathrm{J}$. Du, J. Liu and D. D. Sun, Int. J. Hydrogen Energy, 2011, 36, 6538-6545.

41 S. Xu and D. D. Sun, Int. J. Hydrogen Energy, 2009, 34, 60966104.

42 R. Glicksman, H. Mouquin and C. V. King, J. Electrochem. Soc., 1953, 100, 580-585.

43 H. Irie, S. Miura, K. Kamiya and K. Hashimoto, Chem. Phys. Lett., 2008, 457, 202-205.

44 W. Zhong, N. Yu, L. Zhang, Z. Liu, Z. Wang, J. Hu and Z. Chen, RSC Adv., 2016, 6, 18881-18890.

45 R. Pardo, M. Zayat and D. Levy, Chem. Soc. Rev., 2011, 40, 672-687.

46 S. K. Deb, S.-H. Lee, C. Edwin Tracy, J. Roland Pitts, B. A. Gregg and H. M. Branz, Electrochim. Acta, 2001, 46, 2125-2130.

47 M. Shen and M. A. Henderson, J. Phys. Chem. Lett., 2011, 2, 2707-2710.

48 D. Praveen Kumar, M. V. Shankar, M. Mamatha Kumari, G. Sadanandam, B. Srinivas and V. Durgakumari, Chem. Commun., 2013, 49, 9443-9445.

49 S. S. Lee, H. Bai, Z. Liu and D. D. Sun, Appl. Catal., B, 2013, 140-141, 68-81.

50 G. Lee, M.-K. Yeo, M.-H. Um and M. Kang, Int. J. Photoenergy, 2012, 2012, 10.

51 L. Youngil, C. Jun-rak, L. Kwi Jong, E. S. Nathan and K. Donghoon, Nanotechnology, 2008, 19, 415604. 